\title{
Labelling as a Tool for Improving Animal Welfare-The Pig Case
}

\author{
Jan Tind Sørensen $1, *\left(\mathbb{D}\right.$ and Lars Schrader ${ }^{2}$ \\ 1 Department of Animal Science, Aarhus University, Blichers Alle 20, DK8830 Tjele, Denmark \\ 2 Friedrich-Loeffler Institute, Institute of Animal Welfare and Husbandry, 29223 Celle, Germany; \\ Lars.schrader@fli.de \\ * Correspondence: Jantind.sorensen@anis.au.dk; Tel.: +45-2078-3343
}

Received: 14 May 2019; Accepted: 10 June 2019; Published: 13 June 2019

\begin{abstract}
Market-based promotion of animal welfare has become increasingly important in the EU. Retailers in several countries have implemented graded animal welfare labels for a variety of animal-based products. In this paper, we use labels for pork as a case study and investigate which aspects of animal welfare are promoted by pig welfare labels; we further discuss to what extent labels address the major welfare problems observed in European pig production. Consumers generally focus on aspects of animal welfare related to naturalness, such as outdoor access, straw, and duration of suckling period. Animal welfare labels often address these aspects in addition to other welfare aspects that are of interest to the consumer, such as space, mutilations, confinement, and access to roughage. Major welfare problems such as piglet mortality and weaner diarrhoea are not directly addressed by pig welfare labels. As pig welfare labels often require intact tails, it will also be relevant to address the risk of tail biting and tail lesions. Pig welfare labels, in general, do not use animal-based measures; rather, they are resource-based measures, while animal-based measures are more directly related to animal welfare. Animal-based measures are more difficult and expensive to use in a certification system than resource-based ones. In addition, animal-based measures may be more difficult to communicate to consumers. However, inclusion of animal-based measures would improve reproducibility of labels across production systems and provide documentation on actual levels of major animal welfare problems.
\end{abstract}

Keywords: animal welfare labelling; pig welfare

\section{Introduction}

Animal welfare in intensive livestock production is often confronted with skepticism and concern from the public. Stakeholders in the animal food chain have therefore recognized the importance of animal welfare [1]. In general, there are two ways to promote animal welfare: through legislation or through a market-driven approach that may include a labelling system.

Production methods for animal welfare reasons are regulated through legislation both nationally and in the EU [2]. For example, certain space requirements are stipulated or particular management procedures such as non-curative interventions are prohibited. However, legislation only defines minimal standards, which do not ensure animal welfare, and minimal legal requirements may not meet public expectations with regard to animal welfare. On the other hand, measures to improve animal welfare often increase production costs; thus, the farm animal industry criticizes higher legal national standards as these reduce competitiveness against farmers in countries with lower legal requirements. Consequently, minimal legal requirements are a compromise between public expectations regarding animal welfare and the concerns of producers regarding production costs. 
A legal framework can reinforce a market driven approach. For example, EU legislation has facilitated market segmentation through trade standards for eggs (enriched cages, floor system, and free-range) and through a standardization of organic livestock production. Industry may introduce higher animal welfare standards for the goal of developing a national profile. Examples are Danish and German egg production, which have committed to stopping beak trimming of layers.

Consumers declare that they are willing to pay higher prices for animal products if these are produced under animal friendly conditions $[3,4]$. In recent years, animal welfare labels have been introduced successfully in several European countries [5].

Good animal welfare is something we want for the sake of the animal [6]. There are, however, different perspectives on what is important for good animal welfare. Three different views have been suggested [6].

- Biological function corresponds to definitions of health and is focused on the ability of animals to produce, reproduce, and stay healthy.

- Emotions or affective states, which acknowledges that the animals can feel pain, fear, and frustration.

- Naturalness focuses on the extent to which the animals can behave as they would in nature.

Studies of attitudes toward animal welfare show patterns. Farmers often emphasize the importance of biological function while authorities and animal welfare researchers typically emphasize the importance of animal emotions, while citizens and consumers, without special attachment to agriculture, emphasize the importance of naturalness $[7,8]$. Consumers often express the importance of outdoor access, space, and floor type [1,9]. A recent study indicates that aspects of the housing system, such as straw litter in comparison to fully slatted floors, influence the perception of consumers more than the bodily expressions of pigs, i.e., whether a pig looks "happy" or "unhappy" [10].

The aim of this paper is to consider how animal welfare labels may contribute to improvements in animal welfare, using labels addressing pig welfare as a case study. We will identify major welfare issues in pig production in the EU and discuss whether and how selected animal welfare labels address these issues. In addition, we will discuss how the labels meet consumer expectations. Although there are additional animal welfare concerns regarding animal transport and slaughter, also addressed by labels, we will focus on criteria for the animals on farms. Finally, we will address the European perspective about welfare labels. Dutch, German, and Danish labels on pork are used as case examples.

\section{Current Major Welfare Issues in Pig Production}

In most production systems, pigs are housed and managed according to their stage of production, i.e., sows are kept in the mating, gestation, and farrowing unit (with their piglets). After weaning, weaned piglets $(7-30 \mathrm{~kg}$ ) and finishing pigs (30 kg to slaughter) most often are kept in separate stables. We will structure our consideration of major animal welfare problems according to these production stages.

The main animal welfare problems for each production stage of pigs have been reviewed recently by Pedersen [11] and prior to that by the European Food Safety Agency [12,13]; they are briefly summarized in the following sections.

\subsection{Mating Unit—Sows}

After weaning their piglets, sows are moved to a mating unit. Milk production ceases abruptly and sows come into oestrous a few days after weaning. Most often sows are confined in crates; thus, restriction of movement and lack of social contact are major welfare challenges [11,13]. For sows kept in groups, the floor surface is important due to agonistic and mating behaviours such as mounting [13]. 


\subsection{Gestation Unit-Sows}

According to EU regulations, sows are group-housed from 4 weeks after mating until a few days before expected farrowing. Sows may be in large dynamic groups with individual feeding or in smaller stable groups with competitive feeding. A major welfare problem for pregnant sows is hunger due to a restricted, concentrated diet and insufficient access to foraging/exploration material [11,13]. Further, extended space beyond EU regulation may improve animal welfare for non-lactating sows [14].

\subsection{Farrowing Unit-Sows}

In the farrowing unit, sows are typically housed individually either in crates or in free farrowing systems. Confinement of the sow in a crate during farrowing and lactation may reduce the risk of crushing piglets but result in welfare problems for the sow. The confined sow is hardly able to perform nest building and is not able to move freely during farrowing and lactation [11,13]. Free farrowing sows seem to have few animal welfare problems [15], which is similar to the case for out-door farrowing systems [16]; however, space in the farrowing pen affects sow movement even if the sow is not confined in a crate. A further welfare issue is the availability of nest-building material. Nest-building is a highly motivated behaviour for farrowing sows and cannot be performed if no or insufficient nest-building material is offered $[17,18]$.

\subsection{Farrowing Unit-Piglets}

Welfare problems for piglets relate to large litters with small and weak piglets. In addition, the number of functional teats may not be sufficient to nurse all piglets of a litter. The small and weak piglets are at risk of dying due to crushing, hypothermia, and/or hunger. One measure to improve piglet fitness may be an extended suckling period [19]. Confinement of the sow in a crate during farrowing and lactation may reduce the risk of crushing piglets. Further, tail docking and castration are painful mutilations, decreasing piglet welfare [11]. Free farrowing systems [20] and outdoor farrowing in huts for highly prolific sows [21] may increase piglet mortality compared to crated sows.

\subsection{Weaned Piglets (7-30 kg)}

Weaned pigs are typically housed in groups of various sizes. The welfare problems of weaned pigs relate to the risk of diarrhoea, lack of space, lack of rooting material, and vulnerable pigs due to early weaning [12,22].

\subsection{Finishing Pigs (30 kg to Slaughter)}

Finishers are typically housed in groups of various sizes. The main welfare problems for finishing pigs are lack of rooting material, lack of opportunity for thermoregulation, and tail biting [12]. The risk of tail biting is caused mainly by lack of space and inadequate rooting materials [23]. When kept in common pens with fully slatted floors, pigs with intact tails show significantly more tail lesions compared to tail-docked pigs [24,25].

\section{Pig Welfare Labels-Case Examples}

There are currently several animal welfare labels for pork production in European supermarkets. Here, we will focus on the Dutch label "Beter Leven" [26], two Danish labels "Bedre Dyrevelfærd" ("Better Animal Welfare") [27], and "Dyrevelfærdshjertet" ("The Animal Welfare Heart") [28], the German NGO-Label "Für Mehr Tierschutz" [29], the German "Haltungsform" [30] and the new German "Tierwohlkennzeichen" [31].

The Dutch label "Beter Leven" [26] started in 2007 with chicken and in 2010 with pork. The label has been developed by the animal welfare organization "Dieren Bescherming" and was economically promoted by a large food retailer and a slaughter company. "Beter Leven" [26] has three levels, and the criteria are additive, i.e., the criteria stay or are improved with increasing levels. 
"Better Animal Welfare" [27] for pork has been developed by the Danish Government and is used by many Danish supermarkets since June 2017. "Better Animal Welfare" is a graded label with three levels. The levels of this label are also additive so that all criteria stay or are improved at higher levels.

'The Animal Welfare Heart' [28] has been developed by a Danish retailer group and was started in October 2016. 'The Animal Welfare Heart' [28] is a graded label with four levels. The label is not entirely additive at the criterion level. 'The Animal Welfare Heart' [28] level 4 depends on an individual assessment of a concrete production concept and is therefore a special certification production concept. To achieve level 4, the welfare of pigs has to be assessed on farms and the outcome has to be favourably comparable to all underlying levels for the same product type. Due to this special design for level 4, in the following study we focus only on levels 1, 2, and 3 of "The Animal Welfare Heart".

The German NGO "Deutscher Tierschutzbund" started with the label "Für Mehr Tierschutz" [29] for pork in 2013. This label has two levels and to date only covers requirements for finishing pigs.

The German label "Haltungsform" [30] started in 2019. "Haltungsform" [30] is driven mainly by retailers and integrates already existing labelling schemes as well as the requirements of the German "Initiative Tierwohl". The label "Haltungsform" has four levels. The "Initiative Tierwohl" was introduced in 2015 and is driven and supported by agricultural associations, companies from the meat sector, and food retailers. In the beginning, this initiative did not label the products. Farmers who fulfilled a set of mandatory requirements and/or elective requirements received a certain amount of money from a fund financed by retailers to refinance the extra costs involved, but the produced pork was not sold under a label. The requirements of the "Initiative Tierwohl" address sows, piglets, weaners, and finishing pigs. Currently, the "Initiative Tierwohl" is transferred to the label "Haltungsform" [30] in which the basic and mandatory requirements of the "Initiative Tierwohl" define the second level of the label "Haltungsform". The first level is equivalent to the minimum legal requirements in Germany, the third level is oriented towards the first level of the label "Für Mehr Tierschutz" [29], and the fourth level includes existing premium labels such as organic labels. Until now, the label "Haltungsform" [30] only covers requirements for finishing pigs.

Recently, the German Federal Ministry of Food and Agriculture published the requirements for a governmental welfare label ("Tierwohlkennzeichen") [31] that will be established in the market within the next few years. This label will cover requirements for sows, piglets, weaners, and finishing pigs and will have three levels.

\section{How Do the Pig Welfare Labels Address Major Pig Welfare Problems?}

The pig welfare labels in question address various aspects of animal welfare; however, do they address the major pig welfare problems identified above? An overview of the requirements of the different labels with respect to the major pig welfare problems is given in Table 1 for sows and in Table 2 for growing pigs. 
Table 1. An overview showing how the labels address the major welfare problems in pig production for sows. The labels comprise 3 levels (L), with higher levels indicative of higher standards.

\begin{tabular}{|c|c|c|c|c|c|}
\hline Group of Animals & Welfare Problem & $\begin{array}{l}\text { Beter Leven Three } \\
\text { Levels L1-L3 }\end{array}$ & $\begin{array}{l}\text { Better Animal Welfare } \\
\text { Three Levels L1-L3 }\end{array}$ & $\begin{array}{c}\text { The Animal Welfare Heart } \\
\text { Three Levels L1-L3 }\end{array}$ & $\begin{array}{l}\text { Tierwohlkennzeichen }{ }^{1} \\
\text { Three Levels L1-L3 }\end{array}$ \\
\hline \multirow[t]{4}{*}{ Mating Unit } & Space group housing $\left(\mathrm{m}^{2}\right)$ & L1: 2.25; L2, L3: 2.5 & L1, L2, L3: 2.25 & L1, L2: 2.25, L3: 2.5 & - \\
\hline & Outdoor access (in $\mathrm{m}^{2}$ ) & L1: no; L2: 1.0; L3: 1.9 & L1, L2: no; L3: yes & L1: no; L2: yes; L3: 1.9 & - \\
\hline & Lack of social interaction & $\begin{array}{l}\text { L1, L2, L3: group housing } \\
\text { after } \leq 4 \text { days of fixation }\end{array}$ & $\begin{array}{l}\text { L1, L2, L3: group housing } \\
\text { after } \leq 3 \text { day fixation (L1, } \\
\text { L2). No fixation for L3 }\end{array}$ & L1, L2, L3: group housing & - \\
\hline & Insufficient floor quality & $\begin{array}{c}\text { L1: none } \\
\text { L2, L3: } 1.3 \mathrm{~m}^{2} \text { littered } \\
\text { lying area }\end{array}$ & $\begin{array}{c}\text { L1, none } \\
\text { L2, L3 littered lying area. }\end{array}$ & L1, L2, L3: littered lying area & $\begin{array}{c}\text { L1: none } \\
\text { L2: soft or littered lying } \\
\text { area } \\
\text { L3: littered lying area }\end{array}$ \\
\hline \multirow[t]{4}{*}{ Gestation unit } & $\begin{array}{l}\text { Space (total, including } \\
\text { out-door access, in } \mathrm{m}^{2} \text { ) }\end{array}$ & L1: 2.25; L2: 3.5; L3: 4.4 & L1, L2: 2.25; L3: 3.35 & L1: 2.25; L2: 3.9; L3: 4.4 & - \\
\hline & Outdoor access (in $\mathrm{m}^{2}$ ) & L1: no; L2: 1.0; L3: 1.9 & L1, L2: no; L3: 1.1 & L1: no; L2: 1.1; L3: 1.9 & L1, L2: no; L3: yes \\
\hline & Hunger/restricted feeding & $\begin{array}{l}\text { L1, L2, L3: fibre rich food } \\
\text { or roughage }\end{array}$ & $\begin{array}{l}\text { L1, L2: no rules } \\
\text { L3: roughage }\end{array}$ & L1, L2, L3: roughage & L1, L2, L3: roughage \\
\hline & Lack of rooting material & $\begin{array}{l}\text { L1: plant-based, eatable } \\
\text { L2, L3: straw bedding }\end{array}$ & $\begin{array}{l}\text { L1: access to straw } \\
\text { L2: straw bedding } \\
\text { L3: roughage }\end{array}$ & L1, L2, L3: roughage & $\begin{array}{l}\text { L1, L2, L3: plant-based, } \\
\text { eatable material }\end{array}$ \\
\hline \multirow[t]{4}{*}{ Farrowing unit } & $\begin{array}{l}\text { Space (farrowing pen in } \\
\mathrm{m}^{2} \text { ) }\end{array}$ & L1: 3.8; L2: 6.5; L3: 7.5 & L3: 3.8 & L2: $3.8 ;$ L3: 7.5 & - \\
\hline & Our-door access & no & L1, L2: no; L3: yes & $\begin{array}{c}\text { L1: no; L2: } 300 \mathrm{~m}^{2} / \mathrm{sow} \text {; L3: } \\
\text { yes }\end{array}$ & \\
\hline & Confinement in crate & $\begin{array}{c}\text { L1: yes } \\
\text { L2: } 5 \text { days; L3: } 3 \text { days }\end{array}$ & $\begin{array}{c}\text { L1: } \max 4 \text { days } \\
\text { L2: } \max 2 \text { days; L3: no }\end{array}$ & L1, L2, L3: no & - \\
\hline & $\begin{array}{l}\text { Lack of nest building } \\
\text { material }\end{array}$ & $\begin{array}{l}\text { L1: plant-based } \\
\text { L2, L3: straw litter }\end{array}$ & $\begin{array}{l}\text { L1, L2: access to straw } \\
\text { L3: straw litter }\end{array}$ & $\begin{array}{l}\text { L1: access to straw } \\
\text { L2, L3: straw litter }\end{array}$ & L1, L2, L3: plant-based \\
\hline
\end{tabular}

${ }^{1}$ In Germany, new legal requirements for the mating and the farrowing unit have been announced. Among other requirements, these legal requirements will address the space and duration of fixation. Until the legal requirements are adopted, no requirements in the "Tierwohlkennzeichen" will apply to mating and the farrowing units. 
Table 2. An overview showing how labels address the major welfare problems in pig production for growing pigs. The labels comprise between 2 and 4 levels (L), with higher levels indicative of higher standards.

\begin{tabular}{|c|c|c|c|c|c|c|c|}
\hline Group of Animals & Welfare Problem & $\begin{array}{l}\text { Beter Leven Three } \\
\text { Levels L1-L3 }\end{array}$ & $\begin{array}{c}\text { Better Animal } \\
\text { Welfare Three } \\
\text { Levels L1-L3 }\end{array}$ & $\begin{array}{c}\text { The Animal Welfare } \\
\text { Heart Three Levels } \\
\text { L1-L3 }\end{array}$ & $\begin{array}{l}\text { Für Mehr Tierschutz } \\
\text { Two Levels L1-L2 }\end{array}$ & $\begin{array}{l}\text { Haltungsform }{ }^{1} \text { Four } \\
\text { Levels L1-L4 }\end{array}$ & $\begin{array}{l}\text { Tierwohlkennzeichen }{ }^{2} \\
\text { Three Levels L1-L3 }\end{array}$ \\
\hline \multirow[t]{3}{*}{ Piglets } & Tail docking & $\begin{array}{c}\text { L1: only the tip (>2.5 } \\
\text { cm left) } \\
\text { L2, L3: not allowed }\end{array}$ & $\begin{array}{l}\text { L1, L2, L3: not } \\
\text { allowed }\end{array}$ & $\begin{array}{l}\text { L1, L2, L3: not } \\
\text { allowed }\end{array}$ & L1, L2: not allowed & - & $\begin{array}{l}\text { L1: measures to waive } \\
\text { L2, L3: not allowed }\end{array}$ \\
\hline & Castration & $\begin{array}{l}\text { L1: not allowed } \\
\text { L2, L3: with } \\
\text { anaesthesia \& } \\
\text { analgesia }\end{array}$ & $\begin{array}{l}\text { L1, L2, L3: with } \\
\text { anaesthesia \& } \\
\text { analgesia }\end{array}$ & $\begin{array}{l}\text { L1, L2, L3: with } \\
\text { anaesthesia \& } \\
\text { analgesia }\end{array}$ & $\begin{array}{l}\text { L1, L2, with } \\
\text { anaesthesia \& } \\
\text { analgesia }\end{array}$ & - & $\begin{array}{l}\text { L1, L2, L3: with } \\
\text { anaesthesia \& analgesia }\end{array}$ \\
\hline & Suckling duration (days) & $\begin{aligned} \text { L1: } 23-28 ; ~ L 2: ~ & \geq 35 ; \text { L3: } \\
& \geq 42\end{aligned}$ & $\begin{aligned} \text { L1: } & \geq 21 ; \text { L2, L3: } \\
& \geq 28\end{aligned}$ & $\begin{array}{c}\text { L1: } \geq 28 ; \text { L2: } \geq 30 ; \text { L3: } \\
\quad \geq 40\end{array}$ & - & - & $\begin{aligned} \text { L1: } & \geq 25 \text {; L2: } \\
& \geq 28 \text {; L3: }\end{aligned}$ \\
\hline \multirow[t]{4}{*}{ Weaned piglets } & $\begin{array}{c}\text { Space (total, including } \\
\text { outdoor area- } 30 \mathrm{~kg} \text {, in m²) }\end{array}$ & $\begin{array}{l}\text { L1: } 0.4 ; \text { L2: } 0.5 \\
\text { L3: } 1.0\end{array}$ & $\begin{array}{l}\text { L1: } 0.3 ; \text { L2: } 0.4 \\
\text { L3: } 0.5\end{array}$ & $\begin{array}{c}\text { L1: } 0.4 ; \text { L2: } 0.5 \\
\text { L3: } 1.0\end{array}$ & - & - & $\begin{array}{l}\text { L1: } 0.42 ; \text { L2: } 0.45 \\
\text { L3: } 0.55^{3}\end{array}$ \\
\hline & Outdoor access, $\left(30 \mathrm{~kg}\right.$, in $\left.\mathrm{m}^{2}\right)$ & L1, L2: no; L3: 0.4 & L1, L2: no; L3: 0.17 & $\begin{array}{l}\text { L1: no, L2: } 0.17 ; \text { L3: } \\
0.4\end{array}$ & & & L1, L2: no; L3: yes \\
\hline & Lack of rooting material & $\begin{array}{c}\text { L1: plant-based, } \\
\text { eatable } \\
\text { L2, L3: straw bedding }\end{array}$ & $\begin{array}{l}\text { L1, L2: straw } \\
\text { L3: roughage and } \\
\text { straw }\end{array}$ & $\begin{array}{l}\text { L1: straw } \\
\text { L2, L3: roughage and } \\
\text { straw }\end{array}$ & - & - & $\begin{array}{l}\text { L1, L2, L3: plant-based, } \\
\text { eatable; roughage }\end{array}$ \\
\hline & Diarrhea/poor health & $\begin{array}{c}\text { L1, L2, L3: mortality } \leq \\
1.9 \%\end{array}$ & - & - & - & - & - \\
\hline \multirow[t]{3}{*}{ Finishing pigs } & $\begin{array}{c}\text { Space (total, including } \\
\text { outdoor area- } 110 \mathrm{~kg} \text {, in } \mathrm{m}^{2} \text { ) }\end{array}$ & $\begin{array}{l}\text { L1: 1.0; L2: } 1.8 \\
\text { L3: } 2.3\end{array}$ & $\begin{array}{l}\text { L1: } 0.65 ; \text { L2: } 0.85 \\
\text { L3: } 1.2\end{array}$ & $\begin{array}{l}\text { L1: } 0.85 ; \text { L2: } 1.2 \\
\text { L3: } 2.3\end{array}$ & L1: 1.1; L2: 1.5 & $\begin{array}{l}\text { L2: } 0.825 ; \text { L3: } 1.05 \\
\text { L4: } 1.5\end{array}$ & $\begin{array}{l}\text { L1: } 0.9 ; \text { L2: } 1.1 \\
\text { L3: } 1.5^{3}\end{array}$ \\
\hline & $\begin{array}{l}\text { Outdoor access } \\
\left.\qquad\left(\text { in }^{2}\right)^{2}\right)\end{array}$ & $\begin{array}{l}\text { L1: no } \\
\text { L2: } 0.7 \\
\text { L3: } 1.0\end{array}$ & $\begin{array}{l}\text { L1, L2: no } \\
\text { L3: } 0.5\end{array}$ & $\begin{array}{l}\text { L1: no } \\
\text { L2: } 0.5 \\
\text { L3: } 1.0\end{array}$ & $\begin{array}{l}\text { L1: no } \\
\text { L2: } 0.5 \text { or contact with } \\
\text { outdoor climate }\end{array}$ & $\begin{array}{l}\text { L2: no } \\
\text { L3: contact with } \\
\text { outdoor climate; L4: } \\
\text { yes }\end{array}$ & $\begin{array}{l}\text { L1, L2: no } \\
\text { L3: } 0.5\end{array}$ \\
\hline & $\begin{array}{l}\text { Lack of rooting materials } \\
\text { Insufficient thermal } \\
\text { regulation (in-door systems) }\end{array}$ & $\begin{array}{l}\text { L1: plant-based, } \\
\text { eatable material } \\
\text { L2, L3: straw bedding }\end{array}$ & $\begin{array}{l}\text { L1, L2: access to } \\
\text { straw } \\
\text { L3: roughage }\end{array}$ & $\begin{array}{l}\text { L1: access to straw } \\
\text { L2, L3: roughage }\end{array}$ & $\begin{array}{l}\text { L1: plant-based, } \\
\text { eatable material } \\
\text { L2: straw bedding } \\
\text { L1, L2: air cooling or } \\
\text { water } \\
\text { spraying/evaporation }\end{array}$ & $\begin{array}{l}\text { L2, L3: plant-based } \\
\text { material } \\
\text { L4: straw } \\
\text { L2: none } \\
\text { L3: contact with } \\
\text { outdoor climate }\end{array}$ & $\begin{array}{l}\text { L1, L2, L3: plant-based, } \\
\text { eatable material; } \\
\text { roughage } \\
\text { L1: none, but see text } \\
\text { L2: contact with } \\
\text { outdoor climate }\end{array}$ \\
\hline
\end{tabular}




\subsection{Mating Unit Sows}

Welfare problems in the mating unit listed in Table 1 include space in group housing, outdoor access, lack of social interaction, and insufficient floor quality.

"The Animal Welfare Heart" [28], "Better Animal Welfare" [27], and "Beter Leven" [26] provide social contact due to a request for group housing and restrictions on fixation. "The Animal Welfare Heart" allows no fixation except for a maximum of $2 \mathrm{~h}$ when the sow is inseminated. "Better Animal Welfare" and "Beter Leven' [26] restrict fixation of the sow to 4 days. Space in the stable is increased in "Beter Leven' [26] for levels 2 and 3 and in "The Animal Welfare Heart" [28] for level 3. In addition, "Better Animal Welfare" [27] offers outdoor access for level 2 and "The Animal Welfare Heart" [28] and "Beter Leven" [26] offer additional space in an outdoor area for levels 2 and 3. Floor quality is addressed to some extent though a request for a littered lying area for "Beter Leven" [26] and "Better Animal Welfare" [27] (for levels 2 and 3) and for all three levels for "The Animal Welfare Heart" [28]. In the "Tierwohlkennzeichen" [31], floor quality is only addressed in level 2 (a soft or littered lying area) and in level 3 (a littered lying area is requested).

\subsection{Gestation Unit Sows}

Welfare problems in the gestation unit listed in Table 1 are space, outdoor access, hunger/restricted feeding, and lack of rooting materials.

The "Better Animal Welfare" [27], "The Animal Welfare Heart" [28] and "Beter Leven" [26] labels provide extra space to non-lactating sows (level 3 in "Better Animal Welfare" [27] and in "Beter Leven" [26], and level 2 and 3 in "The Animal Welfare Heart" [28]). Part of the extra space is due to provision of an outdoor area. All levels in "The Animal Welfare Heart", in the "Tierwohlkennzeichen" [31], and for level 3 in "Better Animal Welfare" [27] provide access to roughage. "Beter Leven" [26] provide roughage or fibre rich feed. All labels that include sows are required to offer a certain amount of rooting material.

\subsection{Farrowing Unit Sows}

The welfare problems in the farrowing units for sows listed in Table 1 are space, outdoor access, confinement in crates, and lack of nest building material.

"Beter Leven" [26], "Better Animal Welfare" [27] (level 3), and "The Animal Welfare Heart" [28] (level 2 and 3) offer increased space in the farrowing pen. Sows in "The Animal Welfare Heart" [28] level 2 are kept on pasture, while sows in level 3 are loose housed and have access to an outdoor run. As the requirement for organic sows to be on pasture is a Danish industry requirement and not an EU requirement, "The Animal Welfare Heart" [28] level 3 does not require the sows and their piglets to be on pasture. "The Animal Welfare Heart" [28] requires free farrowing at all three levels without the possibility to confine the sow in a crate. "Better Animal Welfare" [27] (level 1 and 2) and "Beter Leven" [26] (level 2 and 3) provide a free farrowing system with some days of confinement after farrowing. "Better Animal Welfare" [27] level 3 request lactating sows and piglets to be kept in a pasture. All labels including sows require for nest-building material (plant-based material, access to straw, or straw litter).

\subsection{Piglets}

The welfare problems in the farrowing units for piglets listed in Table 2 are tail docking, castration, and suckling duration.

Dutch and Danish labels as well as the German label "Für Mehr Tierschutz" [29] do not allow tail docking, except for the tail tip in "Beter Leven" [26] level 1. "Tierwohlkennzeichen" [31] only allows tail docking at level 1. Castration is only allowed with anaesthesia and analgesia in all labels and levels except from "Haltungsform" [30]. However, in Germany legal castration without anaesthesia and analgesia will be banned anyway in the coming years. In "Beter Leven" [26] level 1, castration 
is not allowed in any case. Four labels provide later weaning ages with increasing levels. "Beter Leven" [26]: 23-28, 35, and 42 days; "Better Animal Welfare" [27]: 21, 28, and 28 days; "The Animal Welfare Heart" [28]: 28, 30, and 40 days; "Tierwohlkennzeichen" [31]: 25, 28, and 35 days.

Confinement of the sow in a crate for a few days after farrowing is allowed in "Better Animal Welfare" [27] (level 1 and 2) and in "Beter Leven" [26] (level 2 and 3). This temporary fixation is presumed to reduce piglet mortality due to crushing.

\subsection{Weaned Piglets $(7-30 \mathrm{~kg})$}

The welfare problems for weaned piglets listed in Table 2 are space, outdoor access, lack of rooting material, and diarrhoea/poor health.

"Beter Leven" [26], "Better Animal Welfare" [27], "The Animal Welfare Heart" [28], and "Tierwohlkennzeichen" [31] offer increased space with increasing levels. Part of the extra space is due to outdoor access, which is given in "Beter Leven" [26], "Better Animal Welfare" [27], in "Tierwohlkennzeichen" [31] at level 3, and in "The Animal Welfare Heart" [28] at level 2 and 3. In the mentioned four labels, rooting material also has to be offered in form of plant-based and eatable material, roughage, or straw. "Beter Leven" [26] includes a threshold for the mortality of weaners. If a farm exceeds a mortality of $1.9 \%$ for one year, a health plan must be developed with a veterinarian to improve the situation. Weaners are not addressed by "Für Mehr Tierschutz" [29] and "Haltungsform" [30].

\subsection{Finishing Pigs (30 kg to Slaughter)}

The welfare problems for finishing pigs listed in Table 2 are space, outdoor access, lack of rooting material, and insufficient in-door thermal regulation.

All labels offer increased space with increasing levels of the respective label. Part of the extra space in all labels is due to outdoor access either for the highest level ("Better Animal Welfare" [27], "Für Mehr Tierschutz" [29], “Tierwohlkennzeichen" [31]), for two levels ("Beter Leven" [26]) or for three levels, ("The Animal Welfare Heart" [28]). In "Für Mehr Tierschutz" [29] a missing requirement for access to outdoors in level 2 can be compensated by a requirement for contact with outdoor climate (e.g., open front stable). In this case, the additional outdoor area has to be offered in the stable. Contact with outdoor climate is also mandatory in level 3 of "Haltungsform" [30]. Regarding rooting material "Better Animal Welfare" [27] (level 2 and 3), "The Animal Welfare Heart" [28] (all levels), and for "Für Mehr Tierschutz" [29] (level 2) requires straw on floor. All other labels require at all levels rooting material such as plant-based and eatable material, straw, or roughage that can be offered for example in racks. Thermal regulation of pigs can be supported by an outdoor run or by contact with outdoor climate, both of which result in different climatic zones. "Für Mehr Tierschutz" [29] explicitly requires technical solutions such as air-cooling or water spraying/evaporation in level 1 in which no outdoor access is required. In level 2 of "Tierwohlkennzeichen" [31], different thermal zones are required that can be obtained either by contact with outdoor climate or by different climatic conditions within the pens, for example, by means of lying boxes or areas with a cooled/heated floor.

\section{Possible Reasons for Differences between Labels}

In general, lack of space is considered a major pig welfare problem which is easy but costly to improve. All labels provide possibilities for buying meat from systems with extra space. Interestingly, the requirements for space differ between the comparable levels of the labels, for example, space for finishers $(110 \mathrm{~kg})$ in the lowest level of the selected label ranges from the minimum legal requirement $0.65 \mathrm{~m}^{2}$ in "Better Animal Welfare" [27] up to $1.1 \mathrm{~m}^{2}$ in "Für Mehr Tierschutz" [29]. There are several possible reasons for such differences: More space is a crucial factor not only for pig welfare but also for production costs. Thus, differences in space requirements may depend on the stakeholders involved in the development of the label. Moreover, the national legal starting point for the labels may differ. For example, the legal minimum requirement for space for a pig (at $110 \mathrm{~kg}$ ) in Denmark is $0.65 \mathrm{~m}^{2}$, in 
Germany it is $0.75 \mathrm{~m}^{2}$, and in The Netherlands it is $0.8 \mathrm{~m}^{2}$; thus, the costs for further increases in space may differ between countries.

An aspect related to space for lactating sows and piglets is free farrowing. The Danish and Dutch labels put an emphasis on free farrowing. This will probably not be required in the German labels, as farmers are afraid of high piglet mortality due to crushing. The Danish pig industry promotes loose lactating sows and has set a target of $10 \%$ of all lactating sows to be loose in 2020 . The Danish government supports by economic incentives farmers investing in loose farrowing systems.

Lack of rooting and enrichment material is observed as a major welfare problem for pigs in general. Straw and/or roughage for rooting and enrichment materials are addressed by all labels. Instead of straw, the farmers in some labels can choose other plant-based material as straw may be difficult to use in systems with liquid manure and straw may be contaminated by mycotoxins. The requirement to offer sufficient and available rooting and enrichment material is difficult to verify. For example, if during a control a trough does not contain any material, it could either be that the pigs just emptied the trough, indicating a good acceptance by the animals, or the farmer did not fill the trough frequently enough, if at all.

Piglet mortality is a major welfare problem for piglets and risk of diarrhoea is a major welfare problem for weaners. These problems are not directly addressed in any of the labels. The Dutch "Beter Leven" [26] requires an annual mortality of weaners lower than $1.9 \%$. If this threshold is exceeded, an animal health plan addressing this problem must be developed with a veterinarian. The Dutch and the German labels address disease problems indirectly by requiring an animal health plan and/or the evaluation of animal-based measures at meat inspection or by means of self-assessment on farms. A reason for not addressing disease problems in the Danish labels might be that, by law in Denmark, there is a request to have an advisory agreement with a veterinarian if a herd exceeds a certain size. This agreement includes annual visits focusing on animal welfare and several visits focusing on animal health and treatment. For Danish sow herds of over 300 sows, it is mandatory to address piglet mortality during animal welfare visits.

The German labels "Für Mehr Tierschutz" [29] and "Haltungsform" [30] currently do not include requirements for sows and weaners. There are three main reasons for that. First, requirements for sows such as more space will drastically increase the costs of pork. In most stables, it is not possible simply to increase the space, for example, for farrowing pens. Larger pens will not fit into the old stables as, for example, the layout of the slurry system will no longer fit. Second, reconstruction of the stable may result in loss of the operation permit for the stable and the building of new stables is hardly possible in certain regions of Germany due to legal requirements for environmental protection. Third, many pig farmers have specialized for certain production phases, for example, farmers may either keep sows and produce piglets or keep finishing pigs. In particular, at the start of a label it may be difficult for a finisher farm to get weaners raised conforming to the requirements of the same level of a respective label. This requires a strong relationship between piglet producers, rearing and finishing farms that often are not established.

In conclusion, buying pork from pig welfare labels facilitates the possibility of reducing major pig welfare problems. The biggest improvements can be achieved at the highest levels, but not at the lower levels. This obviously is related to increasing production costs with increasing levels. None of the labels address all of the major welfare problems identified for pigs. This particularly produces problems such as piglet mortality and diarrhoea in weaners.

\section{Do the Labels Address the Concerns of the Consumers?}

Consumers want naturalness, enabling the pigs to perform their species-specific behaviors [8]. Consequently, all labels provide possibilities for buying meat from systems with outdoor access and extra space. None of the labels prohibit mutilations (castration, tail docking) entirely. In fact, outdoor sows are allowed to be nose ringed in Denmark. The introduction levels of all labels do not offer outdoor access to either sows or growing pigs. Thus, the lower levels for all of the labels investigated may 
not meet the expectations of the consumer regarding naturalness. However, introductory levels give farmers the opportunity to enter the label regime with comparable few changes in their conventional housing conditions. This seems to be important, as label programmes often will not guarantee the farmers a compensation for the costs of the measures needed to improve animal welfare over a time span sufficient for reinvestment of the costs.

A system with welfare-friendly resource-based indicators such as space requirements provides no guarantee of good animal welfare because animal welfare depends to a high degree on daily management; therefore, the use of animal-based measures is generally recommended when assessing animal welfare [32]. However, the labels examined in this study almost exclusively use resource-based indicators. When asking consumers what is important for animal welfare they often suggest resource-based measures such as outdoor access and space [1,9]. Certification is easier and cheaper with resource-based than with animal-based indicators [33]. The farmer can ensure compliance with resource-based indicators whereas animal-based measures such as low levels of lesions, diseases, and mortality are more difficult to ensure. Piglet mortality and incidence of weaner diarrhoea are not directly addressed in any of the labels we have investigated. Recent research indicate that people are worried about production diseases in intensive production systems and that they see medicine-based interventions as least preferred [34]. As many of the labels require intact tails, it is relevant to address the risk of tail bites and tail lesions. Animal-based measures most often focus on the negative aspects of animal welfare whereas resource-based measures, such as outdoor access, longer mother-offspring time, and more space relate to more positive aspects of animal welfare. Even if the outcomes of animal-based indicators can be communicated in a positive manner, e.g., "fewer than $15 \%$ piglet mortality" or "greater than $85 \%$ of piglets survived", this hardly would convince consumers of animal friendly production; however, information on animal-based welfare problems such as shoulder ulcers for sows, tail biting for growing pigs, and piglet mortality may affect the public if these problems reach mainstream media attention. As indicated by Vanhonacker and Verbeke [1], individuals may be more interested in avoiding poor animal welfare rather than seeking out the good; therefore, animal welfare labels need to take into account negative welfare indicators in terms of animal-based indicators to avoid public critique and mistrust. Further positive animal-based indicators, such as for positive emotions, could be considered. However, irrespective of the higher validity of animal-based indicators, the greater effort needed to record them and the need for intensive training of auditors to achieve sufficient reliability still remains a pitfall for their inclusion in labelling schemes [35,36].

\section{Perspectives towards an EU Label for Animal Welfare}

A common EU label for animal welfare would have some obvious advantages. The consumer would not need to address many different labels. In addition, a cross-border trade of label products within the EU could be achieved following standardized requirements and a mutual acceptance of audits. The benefits of an international set of rules can be seen in organic agriculture, with a common EU standard. These benefits are also seen for eggs, for which there are generally accepted standards for animal welfare (enriched cages, floor egg systems, free-range systems, and organic systems). However, our analysis has shown that already, in The Netherlands, in Denmark and in Germany, where the housing conditions of pigs are quite comparable, labelling requirements differ greatly. These differences in part result from the different prerequisites in the requirements between these countries. An EU label could be complicated if it must cover all the different housing systems, different traditional production systems, and different climatic conditions within the EU and only uses resource-based indicators. Thus, despite problems with communication of the outcomes of animal-based indicators and the relatively high costs for controlling them, animal-based measures would help to overcome the differences in housing systems in the EU member states. In addition, because labels promise an improved animal welfare it might be helpful with respect to transparency if the actual status quo of animal welfare can be documented based on animal-based indicators. 
As a starting point, an EU-wide framework could include cheaply collected animal-based indicators such as selected meat inspection measures from abattoirs [37] or other indicators already available, such as the use of antibiotics and mortality. For a consistent EU-wide label with different levels, thresholds for the indicators have to be defined; however, studies show that validity regarding welfare assessment based on data from meat inspection, antibiotic usage, and mortality is still a challenge $[38,39]$. Thus, this approach would require a standardized collection of these indicators that could be achieved either by standardized protocols and training of inspectors or by automatic systems based, for example, using image processing of the carcasses. Moreover, in order to meet the expectations of consumers, animal-based measures need to be combined with resource- and management-based indicators, such as outdoor access. Such a combination of EU-wide consistent requirements based on animal-based indicators in combination with resource- and management-based requirements could help to take into account the abovementioned national differences in tradition, climatic conditions, and consumer expectations. In addition, other aspects, such as the regional origin of products, could be included in this framework of labelling. Thus, although the combination of consistent animal-based indicators with different resource- and management-based indicators could reduce transparency for consumers, it may enable maintenance of a variety of regional differences while remaining based on a consistent principle.

Funding: This research received no external funding.

Conflicts of Interest: The authors declare no conflict of interest.

\section{References}

1. Vanhonacker, F; Verbeke, W. Public and consumer policies for higher welfare food products: Challenges and Opportunities. J. Agric. Environ. Ethics 2014, 27, 153-171. [CrossRef]

2. Veissier, I.; Butterworth, A.; Bock, B.; Roe, E. European approach to ensure good animal welfare. Appl. Anim. Behav. Sci. 2008, 113, 279-297. [CrossRef]

3. European Commission. Attitudes of Europeans towards animal welfare. Spec. Eurobarometer 2016, 442, 60.

4. Clark, B.; Stewart, G.B.; Panzone, L.A.; Kyriazakis, I.; Frewer, L.J. Citizens, consumers and farm animal welfare: A meta-analysis of willingness-to-pay studies. Food Policy 2017, 68, 112-127. [CrossRef]

5. Heerwagen, L.R.; Mørkbak, M.R.; Denver, S.; Sandøe, P.; Christensen, T. The Role of Quality Labels in Market-Driven Animal Welfare. J. Agric. Environ. Ethics 2015, 28, 67-84. [CrossRef]

6. Fraser, D.; Weary, D.M.; Pajor, E.A.; Milligan, B.N. A scientific conception of animal welfare that reflects ethical concerns. Anim. Welf. 1997, 6, 187-205.

7. Sørensen, J.T.; Fraser, D. On-Farm welfare assessment for regulatory purposes: Issues and possible solution. Livest. Sci. 2010, 131, 1-7. [CrossRef]

8. Thorslund, C.A.H.; Aaslyng, M.D.; Lassen, J. Perceived importance and responsibility for market-driven pig welfare: Literature review. Meat Sci. 2017, 125, 37-45. [CrossRef] [PubMed]

9. Janssen, M.; Rödiger, M.; Hamm, U. Labels for Animal Husbandry Systems Meet Consumer Preferences: Results from a Meta-analysis of Consumer Studies. J. Agric. Environ. Ethics 2016, 29, 1071-1100. [CrossRef]

10. Busch, G.; Gauly, S.; von Meyer-Höfer, M.; Spiller, A. Does picture background matter? People's evaluation of pigs in different farm settings. PLoS ONE 2019, 14, e0211256. [CrossRef] [PubMed]

11. Pedersen, L.J. Overview of commercial pig production systems and their main welfare challenges. In Advances in Pig Welfare; Spinka, M., Ed.; Woodhead Publishing: Sawston, UK, 2018; pp. 3-26. ISBN 978-0-08-101012-9.

12. European Food Safety Authority (EFSA). Scientific opinion of the panel on animal health and welfare on a request from the Commission on animal health and welfare in fattening pigs in relation to housing and husbandry. EFSA J. Annex 2007, 564, 1-14.

13. European Food Safety Authority (EFSA). Scientific opinion of the panel on animal health and welfare on a request from the Commission on Animal health and welfare aspects of different housing and husbandry systems for adult breeding boars, pregnant, farrowing sows and unweaned piglets. EFSA J. Annex 2007, 572, $1-13$. 
14. Verdon, M.; Hansen, C.F.; Rault, J.L.; Jongman, E.; Hansen, L.U.; Plush, K.; Hemsworth, P.H. Effects of group housing an sow welfare. A review. J. Anim. Sci. 2016, 93, 1999-2017. [CrossRef] [PubMed]

15. Singh, C.; Verdon, M.; Cronin, G.M.; Hemsworth, P.H. The behaviour and welfare of sows and piglets in farrowing crates or lactation pens. Animal 2017, 11, 1210-1221. [CrossRef] [PubMed]

16. Leeb, C.; Rudolph, G.; Bochicchio, D.; Edwards, S.; Früh, B.; Holinger, M.; Holmes, D.; Illmann, G.; Knop, D.; Prunier, A.; et al. Effects of three husbandry systems on health, welfare and productivity of organic pigs. Animal 2019, in press. [CrossRef] [PubMed]

17. Arey, D.S.; Petchey, A.M.; Fowler, V.R. The preparturient behaviour of sows in enriched pens and the effect of pre-formed nests. Appl. Anim. Behav. Sci. 1991, 31, 61-68. [CrossRef]

18. Andersen, I.L.; Vasdal, G.; Pedersen, L.J. Nest building and posture changes and activity budget of gilts housed in pens and crates. Appl. Anim. Behav. Sci. 2014, 159, 29-33. [CrossRef]

19. Madec, F.; Bridoux, N.; Bounaix, S.; Jestin, A. Measurement of digestive disorders in the piglet at weaning and related risk factors. Prev. Vet. Med. 1998, 35, 53-72. [CrossRef]

20. Hales, J.; Moustsen, V.A.; Nielsen, M.B.F.; Hansen, C.F. Higher preweaning mortality in free farrowing pens compared with farrowing crates in three commercial pig farms. Animal 2014, 8, 113-120. [CrossRef]

21. Rangstrup-Christensen, L.; Krogh, M.A.; Pedersen, L.J.; Sørensen, J.T. Sow level risk factors for early piglet mortality and crushing in organic outdoor production. Animal 2018, 12, 810-818. [CrossRef]

22. Verdon, M.; Rault, J.L. Aggression in group housed sows and fattening pigs. In Advances in Pig Welfare; Spinka, M., Ed.; Woodhead Publishing: Sawston, UK, 2018; pp. 235-260. ISBN 978-0-08-101012-9.

23. Valros, A. Tail Biting; Spinka, M., Ed.; Woodhead Publishing: Sawston, UK, 2018; pp. 137-166, ISBN 978-0-08-101012-9.

24. Dippel, S.; Schrader, L. Tail docking in pigs-status quo in Germany. Züchtungskunde 2016, 88, 417-428.

25. Kongsted, H.; Sørensen, J.T. Lesions found at routine meat inspection on finishing pigs are associated with the pig production system. Vet. J. 2017, 223, 21-26. [CrossRef] [PubMed]

26. Beter Leven. Available online: https://beterleven.dierenbescherming.nl/ (accessed on 16 March 2019).

27. Bedre Dyrevelfærd (Better Animal Welfare). Available online: https://www.foedevarestyrelsen.dk/ kampagner/Bedre-dyrevelfaerd/Sider/Information-in-English.aspx (accessed on 16 March 2019).

28. Dyrevelfærdshjertet (The Animal Welfare Heart). Available online: http://dyrevelf $1 \mathrm{~T} 1$ aerd.coop.dk/ dyrevelfaerdshjertet/?gclid=EAIaIQobChMIgbWZ_a-B4QIVxYGyCh3SPg79EAAYAiAAEgJVXvD_BwE (accessed on 16 March 2019).

29. Für Mehr Tierschutz. Available online: https://www.tierschutzlabel.info/fileadmin/user_upload/Dokumente/ Mastschweine/RL_Mastschweine_2017.pdf (accessed on 16 March 2019).

30. Haltungsform. Available online: https://www.haltungsform.de/ (accessed on 16 March 2019).

31. Tierwohlkennzeichen. Available online: https://www.bmel.de/SharedDocs/Downloads/Tier/Tierwohl/ Tierwohlkennzeichen_Schwein_Kriterien.pdf?_blob=publicationFile (accessed on 16 March 2019).

32. European Food Safety Authority (EFSA). Statement on the use of animal-based measures to assess the welfare of animals. EFSA J. 2012, 10, 29.

33. Sørensen, J.T.; Rousing, T.; Møller, S.H.; Bonde, M.; Hegelund, L. On-Farm welfare assessment systems: What are the recording costs? Anim. Welf. 2007, 16, 237-240.

34. Clark, B.; Panzone, L.A.; Stewart, G.B.; Kyriazakis, I.; Niemi, J.K.; Latvala, T.; Tranter, R.; Jones, P.; Frewer, L.J. Consumer attitude towards production diseases in intensive production systems. PLoS ONE 2019, 14, e0210432. [CrossRef] [PubMed]

35. Pfeifer, M.; Eggemann, L.; Kransmann, J.; Schmitt, A.O.; Hessel, E.F. Inter-And intra-Observer reliability of animal welfare indicators for the on-Farm self-Assessment of fattening pigs. Animal 2019, in press. [CrossRef] [PubMed]

36. Croyle, S.L.; Nash, C.G.R.; Bauman, C.; LeBlanc, S.J.; Haley, D.B.; Khosa, D.K.; Kelton, D.F. Training method for animal-based measures in dairy cattle welfare assessments. J. Dairy Sci. 2018, 101, 9463-9471. [CrossRef] [PubMed]

37. Van Staaveren, N.; Doyle, B.; Hanlon, A.; Boyle, L.A. Multi-stakeholder focus groups on potential for meat inspection data to inform management of pig health and welfare on farm. Agriculture 2019, 9, 40. [CrossRef] 
38. Nielsen, S.; Denwood, M.; Forkman, B.; Houe, H. Selection of meat inspection data for an animal welfare index in cattle and pigs in Denmark. Animals 2017, 7, 94. [CrossRef] [PubMed]

39. Knage-Rasmussen, K.M.; Rousing, T.; Sørensen, J.T.; Houe, H. Assessing animal welfare in sow herds using data on meat inspection, medication and mortality. Animal 2015, 9, 509-515. [CrossRef]

(C) 2019 by the authors. Licensee MDPI, Basel, Switzerland. This article is an open access article distributed under the terms and conditions of the Creative Commons Attribution (CC BY) license (http://creativecommons.org/licenses/by/4.0/). 